\title{
Hacia un sistema de co-responsabilidad penal juvenil situado Osvaldo Marcón
}

Osvaldo Marcón es profesor de la Escuela de Trabajo Social de Santa Fe y de la Universidad Adventista de La Plata.

Mail:omarcon@arnet.com.ar

\section{resumen}

A partir de la vigencia de la Convención Internacional sobre los Derechos del Niño, el modo en que el Estado debe reaccionar frente a delitos cometidos por ciudadanos menores de edad es objeto de discusión. El Garantismo se presenta, a través de la idea de la responsabilización penal, como solución universal que, así, no contempla singularidades locales y atenta contra su pretensión garantista originaria. Dado que abre posibilidades a nuevas formas de tutelarepresiva es necesario profundizar la discusión, detectando contradicciones y evitando dar por naturales algunos dominios conceptuales hegemónicos. No se trata de un problema solamente jurídico sino que está relacionado con un proyecto de Nación.

\section{summary}

The way in which the State should deal with crimes committed by minors has been subject to discussion since the Convention on the Rights of the Child enforcement. The concept of garantismo viewed from the idea of criminal liability is introduced as a universal solution that disregards unique local features; restrains the original guaranties to be protected; and, leads to possible new ways of repressive guardianship. Therefore, it is necessary a deeper discussion in order to detect contradictions and avoid the naturalization of certain hegemonic conceptual domains. This is not a question including just legal issues; it also involves a Nation project.

\section{palabras clave}

delito / jóvenes / derechos / penas / responsabilidad

\section{keywords}

crime / youth / rights / penalties / liability 


\section{1) Acerca del objeto en discusión}

En gran parte del mundo, y particularmente en la República Argentina, algunas discusiones tomaron nuevas formas desde que la Convención Internacional sobre los Derechos del Niño (CIDN) fue emplazada como marco regulador de las políticas públicas para la niñez. Distintas ideas pasaron a ser consideradas anacrónicas frente a otras, ahora novedosas. En dicho contexto cobra centralidad el esfuerzo por proporcionar a todo niño un tratamiento estatal no violatorio de distintas garantías constitucionales, posición que es acompañada por diversos colectivos profesionales pues excede ampliamente lo estrictamente jurídico para constituirse como dimensión ideológica, política y teórica, entre otras.

La que podríamos denominar lógica previa a la CIDN es recordada, aunque no excluyentemente, señalando con énfasis distintas intervenciones que judicializaban tanto al niño en situación de riesgo ${ }^{1}$ como al niño que, estando o no en dicha situación, protagonizaba hechos penalmente tipificados (delitos). En este contexto, exponiendo legalmente la pretensión de proteger a los sectores infantiles socialmente vulnerados, el Estado promovía acciones tutelares que llevaba adelante haciendo uso de su fuerza. Generaba así un esquema de funcionamiento que algunos autores denominaron tutelar-represivo pues el primer componente (tutelar) adquiría un carácter residual frente el segundo (represivo) que ganaba en omnipotencia. Tanto los niños pensados como objeto de compasión por su situación social como aquellos que cometían delitos eran tratados de igual manera. Con esta lógica apareció cierta re-victimización centrada en distintas formas y grados de privación de la libertad ambulatoria que tomaba cuerpo en instituciones de internación corrientemente conocidas como asilos, orfanatos o institutos, entre otras denominaciones utilizadas. Así se configuró la mencionada matriz de pensamiento también denominada "compasiva-represiva" (García Méndez, 2006: 1), caracterizada por la combinación de una pretendida protección que muta en reprimenda social al ser aplicada, cuando no lo es en su origen mismo.

Se advierte que ante esta expresión de la cuestión social o -dicho de otro modoante la sociedad expresando "el enigma de su cohesión" (Castel, 2004: 20) a través de la niñez socialmente excluida el Estado reaccionaba con la fuerza judicial. La lógica de la CIDN propone retirar dicha fuerza aplicada sobre esta forma de exclusión social para, en su lugar, impulsar la intervención a través de políticas sociales. Esta estrategia está particularmente referida a la situación de los niños que expresan la mencionada problemática de cohesión social sin llegar a exteriorizar actos penalmente tipificados. Pero para aquellos niños que aún formando parte de la misma expresión cometen delitos, la reacción estatal es otra. Se construye un objeto específico de intervención asentado en la punibilidad como factor decisivo, por lo que dicho objeto tiende a ser caracterizado como penal. Unas edades particulares y unos hechos específicos, en condiciones también especiales, harán que el niño pueda ser penalizado pero para ello debe garantizársele un proceso judicial justo, lo que equivale a decir adecuado según las garantías constitucionalmente vigentes para los adultos.

Causalidad compleja mediante, el debate ensancha toda su fuerza en la construc- 
ción de estos dos caminos: Los 'niños pobres' deben ser objeto de las políticas sociales y los 'niños delincuentes' deben ser objeto de la intervención penal. Estas dos tendencias simultáneamente resisten, con cierta nitidez, toda posibilidad de bifurcación de esos caminos que podría compatibilizarse con cierta complejidad causal. Por ejemplo, casi no se piensa en términos de 'niños en situación de pobreza' como tampoco se admite que, en realidad, el camino penal también está generalmente referido a 'niños en situación de pobreza'. La mayor parte de los actores del sistema corrientemente dicen saber que el sistema judicial capta mayoritariamente a niños pobres ${ }^{2}$ pero esto no se plasma en las distintas conceptualizaciones. No se admite, entonces, que así dadas las cosas se discute respecto de una abstracción -los 'niños delincuentes'- sin que tenga lugar la problematización de la misma para reconocerlos, reiterando el ejemplo utilizado, como 'niños en situación de pobreza'.

Ahora bien ¿qué importancia puede tener esta caracterización? Se trata de un aspecto decisivo pues las garantías constitucionales varían substancialmente según las condiciones en las cuales se piensa su ejercicio. Enhorabuena, es la preocupación por la vigencia de estas garantías la que motoriza los aspectos positivos de las aludidas transformaciones. Sin embargo, no se trata de leyes (normas jurídicas, en este caso) que inexorablemente, y con prescindencia de los contextos, resultarán eficaces asegurando con ello un trato igualitario de todos los ciudadanos. El propio Luigi Ferrajoli (1995), en su ya muy conocida obra "Derecho y Razón: Teoría del Garantismo Penal", manifiesta su preocupación entre, por un lado, lo que puede llamarse cierta especie de "Garantismo Teórico" y, por otro lado, el "Garantismo Real". Esto es así por diversas razones pero fundamentalmente porque las ciencias del campo jurídico, parte constitutiva de las ciencias sociales, no pueden "producir conocimientos que expresen relaciones invariantes que regulen los fenómenos humanos" (Heler, 2005: 91). Las condiciones en que se producen y/o reproducen dichas relaciones transforman a estas últimas en variantes alterando, inclusive, la posibilidad de materialización de las mismas. Por ejemplo, a un niño que no esté en situación de pobreza es más factible garantizar una defensa técnicamente adecuada pero ¿podría sostenerse esto respecto de un niño en situación de pobreza? Como se sabe en estas sociedades, con estas formas de capitalismo y -entonces- con estas formas de producción y consumo quien dispone de recursos económicos puede contratar servicios de mayor calidad por lo que aumentan sus posibilidades de éxito.

Se advierte así cuán importante es reconocer la necesidad de diversificar los enfoques para superar, inclusive, cierto amesetamiento ${ }^{3}$ en la producción de conocimiento que abona las prácticas institucionales. Pareciera operar un supuesto según el cual formuladas las invariantes sólo resta esperar que ellas actúen con la eficacia de -por ejemploaquella ley de la Física según la cual los objetos se atraen entre sí con fuerza constante lo que posibilita, según lo formulara Isaac Newton (1643/1727), que todo objeto en caída libre lo haga con la fuerza gravitatoria de la Tierra. Recordemos, en esto de subrayar la variancia de las invariancias, que aún en el campo de la Física la teoría de Newton fue revisada por Albert Einstein (1879/1955) mediante la Teoría de la Relatividad General, crítica que forma parte de un proceso al que se suman los hallazgos de la denominada Física Cuántica, más otros significativos aportes como la Teoría del Caos 
que encuentra a su principal precursor en Ilya Prigogine (1917/2003). Pues bien, si ni siquiera el más duro de los campos -el de la Física- logra ser conocido a través de ideas invariables ¿cómo pretenderlo para esta porción de las ciencias sociales? Esta lógica seduce bajo la promesa de lograr la eficacia taxativa de las garantías constitucionales prescindiendo de las particularidades situacionales. He aquí parte del núcleo duro en el que se asienta la arquitectura de este trabajo.

El mencionado amesetamiento no implica que nada se desarrolla sino que lo que se produce no avanza significativamente en los aquí anhelados términos de diversificación, particularmente con relación a la intervención penal sobre los referidos sectores de la niñez. Este trabajo intenta llamar la atención respecto de aspectos de esta cuestión desde un plano evaluativo aún cuando la forma que dicho proceso adquiere incorpora, necesariamente, algunas consideraciones de orden prospectivo, particularmente hacia el final del artículo. Recurriremos para ello, en primer lugar, al trascendente aporte de Mario Casalla mediante la categoría conocida como universal situado.

\section{2) La cuestión en coordenadas históricas}

Avancemos en este recorrido trayendo a colación que el proceso de globalización nos coloca frente a la potencialidad del globalitarismo (Casalla, 2004a: 80) entendido como potencial peligro imperialista de rango planetario. En concordancia con tal afirmación se advierten mutaciones en diversos órdenes de lo conceptual con impacto, claro está, en el orden de lo real. Podría decirse inclusive que varias de tales mutaciones son condición necesaria de dicha tendencia globaritarista. Las variaciones en la producción capitalista (del fordismo al post-fordismo), el neo-avance del ideario liberal en sus dimensiones política, económica, cultural y civilizatoria, o sea la profundización del "individualismo contemporáneo" (Lipovetsky, 1995: 5), son ejemplos de dimensiones en las que se observa unidad substancial entre algunos conceptos cotidianamente dominantes y la globalización en tanto situación macro.

De forma más o menos explícita estas transformaciones promueven ideas-fuerza que participan activamente en el desarrollo de distintos contextos. Éstos, a su vez, consolidan aquellas mutaciones estableciendo un orden simbólico instituyente de lo social. Al respecto recordemos, en términos de Castoriadis (1993: 118), que "la institución de la sociedad es institución de un mundo de significaciones que es, evidentemente, creación como tal y creación especifica en cada momento". Cual levaduras que actúan sin prisa pero sin pausa dichas mudas conceptuales preparan el terreno en el que germinan distintos idearios y son, simultáneamente, fieles herramientas para la labranza ideológica. Se observa así la eficaz construcción de un "orden simbólico" (Casalla, 2004a: 77) que funciona cual "ficción orientado$r a$ " en los términos enunciados por Nicolás Shumway (1993) a quien citaremos nuevamente más adelante.

Como se adelantara en este trabajo, de tales ficciones orientadoras nos interesa una en particular, atrapada bajo la idea de la "responsabilización penal juvenil". A primera vista se la asocia con el campo de lo jurídico pero si bien es innegable 
dicha pertenencia también es innegable su participación en un substrato civilizatorio que posibilita tal modo de pensar. Digamos que si tal ficción formara parte de un conjunto de invenciones coherentes entre sí, constitutivas de un proyecto integral e integrado situacionalmente a la realidad latinoamericana, estudiaríamos la posibilidad de darle la bienvenida. Sin embargo se trata de una ficción impuesta desde un orden con pretensiones universalistas que, entonces, hace de la responsabilización un artefacto extranjero.

La relevancia de esta idea se potencia si coincidimos con lo escrito por Shumway en "La invención de la Argentina". Allí pone en evidencia cómo es que históricamente se advierte en los países de la América hispánica un importante déficit en la construcción de ficciones orientadoras que den cuenta de sus específicas realidades. Precisamente escribe que "en Europa, y hasta cierto punto en los Estados Unidos, los mitos de nacionalidad sobre los que podían construirse las naciones existían antes de que se formaran las naciones mismas" (Shumway, 1993: 20). Refiere como ejemplo, en el caso de EE.UU., la transformación de importantes postulados religiosos en convicciones de alta eficacia en el orden de la organización social y productiva. Argentina por su parte, como otros países latinoamericanos, prolongó los estrechos lazos sociales, políticos e ideológicos con España por lo que las ideas propias de nacionalidad recién tomaron forma en el siglo XIX. En esta época un cuerpo diversificado de ideas nacionalistas (Artigas, Rosas, Güemes, entre otros) constituyó un primer esbozo de ficción orientadora. Otro, visiblemente más estable, se conformó en torno al pensamiento liberal del que Sarmiento y Mitre fueron significativos exponentes. Estos últimos pensaban desde Buenos Aires teniendo a Europa y EE.UU. como modelos a imitar. Por ello forjaron un conjunto de ideas rectoras altamente excluyentes, y signaron a sus enemigos como bárbaros, enemigos del progreso e inclusive racialmente inferiores. Los primeros (nacionalistas), más diversos en sus formulaciones y en ocasiones contradictorios, no llegaron a oponerse a los segundos (liberales) desde una idea unificada. Por ello la primera versión de un proyecto nacional será la de la Generación del 80, expresión triunfante del liberalismo como ficción orientadora.

Resulta indispensable tener presentes tales trazos históricos para ensayar respuestas a una multiplicidad de expresiones sociales que, bajo distintas fachadas, se mantendrán hasta fines del siglo XIX y -aunque en ocasiones reconfiguradasdurante el siglo XX y lo que va del XXI. Es en aquel periodo (s. XIX), dominado por las políticas inmigratorias orientadas a mejorar la sangre criolla con cultura europea, que se gestan las protoformas de la matriz de pensamiento que luego se identificaría como "compasiva-represiva" (García Méndez, 2006: 1) o, dicho en otros términos, la ideología tutelar-represiva. De acuerdo a lo esbozado en el primer punto de este artículo, se trata de formas de intervenir sobre la situación de las infancias socialmente excluidas que, al crecer demográficamente los grandes centros urbanos, se transforman en una preocupación pública, altamente visible, de la que ya no pueden dar cuenta las formaciones sociales de caridad y/o beneficencia. La tarea de éstas es entonces tomada por el Estado cobrando centralidad -ya en el siglo XX-su herramienta jurídica por excelencia conocida como Ley Agote o 
Ley del Patronato del Estado. Estas intenciones aparentemente benévolas dieron lugar a diversas prácticas de conculcación de derechos. La creación de instituciones de gran tamaño para el alojamiento de estos niños generaron una diversidad de sombrías realidades homologables a las identificadas en el ya clásico texto "Internados" (Goffman, 2004). No es necesario abundar en detalles pero baste con mencionar que en dicho esquema era vulnerado mucho más que el derecho a la libertad ambulatoria.

Estos niños ocupaban, en la ficción orientadora dominante, el lugar de lo no deseado, lo no tolerado, lo no aceptado. Quizás podríamos decir que, ya desde antes de la Ley Agote, ocupaban el lugar de los pequeños bárbaros destinados a ser los grandes bárbaros del mañana. En estos pequeños bárbaros latía la condición mestiza. Mezcla de hábitos venidos de los barcos (inmigrantes), con más historias negras e indígenas, dieron lugar a realidades locales ante las cuales la visión liberal, admiradora de Europa y EE.UU., nunca fue capaz de encontrar respuestas en términos de construcción de una ficción situada. El ya citado Shumway devela cuántas dificultades hubo -y sigue habiendo, decimos aquí- para comprender lo autóctono desde categorías con pretensiones universales. En tono de 'pie de pági$n a$ 'citemos, en relación a las dificultades para comprender lo autóctono, un pasaje en la obra de Shumway (1993: 29): "tan atractivo era el modo de vida despreocupado de los gauchos que en 1807, durante la ocupación inglesa de Buenos Aires, 170 soldados ingleses desertaron para vivir entre ellos". He allí un holograma del cortocircuito intercultural que venimos tratando de abordar. ¿De qué responsabilidad en general hablamos y, en particular, qué responsabilidad penal juvenil es la exigible dada nuestra especificidad situacional? ¿Cómo es que productos altamente regimentados (militares ingleses) caen seducidos ante la "holgazanería" criolla? ¿Qué significaciones laten en términos culturales?

\section{3) La necesidad de situar la cuestión}

La admiración por el modo de ser europeo (y norteamericano) de aquella ficción orientadora liberal no surge casualmente. Por el contrario, forma parte de un proyecto más abarcador, de origen no latinoamericano. La propia Europa se consideraba a sí misma como un "modelo universal para todas las culturas" (Casalla, 2003: 235). Esta pretensión se asentaba en la firme convicción respecto de un supuesto mandato racional que le era propio y la diferenciaba de pueblos sin este substrato. Dicho de otro modo, domina la idea de que otros pueblos "carecerían de ese télos racional que sólo Europa representa y patentiza" (Ídem: 237). Es en medio de dicho contexto histórico que en Argentina la Ley Agote opera como porción de una ficción que no da cuenta de las singularidades locales. Y es en dicho lugar simbólico donde lo tutelar adquiere su paradojal significación represiva. Queda abierto un conjunto de preguntas cuyas respuestas no ensayaremos pues nos alejarían del eje: ¿pudo ser, en otra situación, no represivo lo tutelar? Sabemos que este concepto -la tutela- remite en ciencias sociales a figuras que contradicen la promoción de la autonomía del Sujeto Social y, en particular, sus Derechos Humanos pero ¿en qué contextos? 
Dejemos abiertas estas preguntas y volvamos a la cuestión de la responsabilización penal juvenil. Se trata, en el aquí y ahora, de una construcción conceptual asentada sobre la idea de obtener respuesta, o de que el sujeto responda, como eje genérico que con cierta regularidad es reforzado desde diversos órdenes institucionales (organismos internacionales, cientistas significativos, empresas privadas, grandes medios de comunicación, entre otros). Pero esta construcción también se rejuvenece cotidianamente pues, a primera vista, dicha exigencia pareciera indiscutible: es obvio que todo ciudadano debe 'ser responsable' en medio de un conjunto de ideas instaladas sin discusión pero que, a poco de ser problematizadas, exhiben su parentesco con aquella ficción orientadora liberal. Pero entonces ¿qué implica pensar esto en nuestra situación? ¿Se trata de un discurso responsabilizante que favorece el desarrollo de un orden social más justo o, por el contrario, tiende a cristalizar sus actuales deficiencias? ¿Es 'justo', paradójicamente, depositar en dicha categoría conceptual la 'responsabilidad' de transformar o, al menos, mejorar el actual estado de cosas? Y más aún: ¿es factible la responsabilización plena de sujetos, grupos o comunidades, con estas particularidades locales pero en función de credos con pretensiones universalistas? ¿Pueden y deben los jóvenes 'hacerse responsables' de lo que les sucede y/o de lo que supuestamente 'ellos provocan’? ¿En qué grado? ¿Cuáles son las cotas de esta responsabilización? ¿Y qué respuestas corresponde discutir para la situación de jóvenes que han ingresado en un campo de conflicto para con 'el orden jurídico-penal? ¿Se trata, en definitiva, de un sistema de ideas idóneo para intervenir en nuestra realidad sin problematización previa? En definitiva, ¿reconcilia o profundiza el abismo sintetizado en la expresión 'civilización o barbarie'?

Estos interrogantes reconfiguran viejos sentidos y promueven algunos nuevos pues en el escenario del que formamos parte la idea de responsabilizar aparece con una importante carga moralizante que guarda estrecha relación con determinado orden de producción y consumo, esto es con un orden social específico. En definitiva, aquellos muy europeos soldados que abandonaron el ejército inglés para pasar a vivir como gauchos, atentaron más contra el reluciente capitalismo que contra sus jerarcas militares. "El general Whitelocke se quejaba: Cuanto más conocen los soldados de las riquezas que provee el país, y la facilidad con que se las obtiene, mayor el peligro" (Shumway, 1993: 29).

Este modo de pensar la responsabilidad no ha sido construido con elementos contemporáneos exclusivamente sino que hunde algunas de sus raíces en diversas tradiciones que incluyen tanto la religiosidad medieval como el secularismo liberal. La condición de sujeto 'irresponsable' remite, automáticamente, a un lugar degradado en el imaginario social, sitio totalmente opuesto a la puritana ficción orientadora que anteriormente presentamos como propia de EE.UU. No se trata de negar la necesidad de un sujeto social que en cuanto tal responda por sus actos, pero sí de sostener la necesidad de un proceso de des-naturalización. El irresponsable no es, necesariamente, quien decide libremente no asumir responsabilidades sino que dentro de dicha irresponsabilidad aparecen múltiples matices que podríamos resumir en la noción de poder para asumir responsabilidades. La queja 
de Whitelocke en relación a la conducta de los soldados ingleses muestra dicha situacionalidad de la responsabilidad. Para des-naturalizarla elegimos el camino de la lectura culturalmente situada, lo que supone ubicar el pensamiento para "comprenderlo dentro de aquella estructura histórica... en relación con la cual éste se expresa y dentro de la cual adquiere su especificidad" (Casalla, 2004b: 5).

Ahora bien, y retomando la idea central: asistimos al reemplazo maniqueísta de aquella ideología tutelar-represiva por una visión global-occidental del problema que incluye un importante grado de cerrazón teórica concordante -como decíamos- con la citada tendencia al globalitarismo, de ubicación de lo único en el lugar de lo diverso. Se trata de una idea de responsabilización que tiende a ser impuesta, en concordancia con la expansión de la lógica liberal a nivel mundial y uno de sus anversos, constituido por la lógica penal burocratizada, meramente represiva antes que garante de derechos, impulsada fundamentalmente por EE.UU. (Wacquant, 2000). Frente a dicha estrategia se requiere invertir la carga de trabajo intelectual para incorporar los beneficios de una concepción evidentemente comprometida con el avance de los Derechos Humanos, pero impidiendo su transformación en fachada que con los mismos argumentos obture el avance en términos de concreción de los mismos.

Así es que, con la idea no situada de responsabilización penal juvenil, podríamos estar frente al riesgo de re-editar las matrices de pensamiento separatistas ("civilización o barbarie"). Aquella lógica tutelar-represiva de principios del siglo XX significó errores y horrores que duraron al menos un siglo por, precisamente, tratarse de una lógica no situada en nuestra realidad, exacerbando el valor de la mirada puesta en Europa. Estos errores y horrores son tan graves como los errores y horrores de, a cien años, no situar el análisis de lo ocurrido. La reformulación separatista es uno de tales peligros pues en el actual contexto mundial, aunque en evidente tensión hacia un mundo multipolar, política e ideológicamente más diverso, la matriz liberal sigue dominando las relaciones sociales. Recordemos el riesgo del globaritarismo, expuesto por Casalla. Es en este contexto global-liberal que aparece la propuesta de la responsabilización penal juvenil como hito del pensamiento occidental en general, y del "saber penal" (Zaffaroni, 2007: 17) en particular.

Ni Europa ni el liberalismo local son los mismos de hace uno o dos siglos pero conservan cuestiones substanciales. Existen diversos indicadores de los que no daremos cuenta aquí pues son públicamente conocidos como por ejemplo, entre otras, las recomendaciones de organismos internacionales especializados, fundamentalmente los dependientes de Naciones Unidas. Otra muestra es el dictamen del Comité Económico Social Europeo (CESE) del año 2006 que destaca, con cierto énfasis, cómo la Unión Europea en su conjunto avanzó hacia lo que, precisamente, se conoce como "modelo de responsabilidad" (CESE, 2006). Vemos así que o unos o los otros no están pensando el problema situacionalmente. Nos preocupa prioritariamente, no obstante, la dimensión local de dicha falencia epistemológica pues estaríamos ante una nueva y desesperada búsqueda por ocupar con trozos de ficciones ajenas los angustiantes lugares de nuestras faltas. Esta 
ausencia de una firme identidad provoca trágicos deslices y preocupa aún más si advertimos que -como escribiera Casalla- "no hay, en este sur del Sur, una identidad perdida que rescatar como en muchos lugares del resto de América Latina" (Casalla, 2006: 5).

Todo está por hacerse y, ante esta tarea, se repite una y otra vez la tendencia a profundizar la brecha cultural antes que a suturarla. La observación de lo cotidiano pone en evidencia cómo las estructuras de pensamiento que forja la ficción liberal llevan, en sí mismas, por un camino que tranquiliza a un lado de la brecha pero profundiza las injusticias del otro lado. Así crecen los 'como si', es decir los artilugios que simulan ser lo que no son, particularmente en relación con el campo del que forma parte nuestro objeto de estudio, tocando en ocasiones los límites del absurdo. Rodolfo Kusch escribía magistralmente hace décadas que "el formalismo en el derecho, en la burocracia, en las letras, en el arte, más que formas frías evocan rituales esotéricos" (Kusch, 1998: 50).

\section{4) Algunos rasgos de tal situacionalidad}

Desde una tradicional perspectiva con cierta pretensión universalista podríamos recordar que el término responsabilidad se asocia etimológicamente a la voz 'responsum', forma latina del verbo 'responder'. En principio podemos considerar entonces que 'responsabilidad'es la “habilidad de responder". El Diccionario de la Real Academia Española prescribe diversas significaciones de las que destacamos la idea de 'responsabilidad' como “cualidad de responsable”. La obra alude también a la noción de "deuda, obligación de reparar y satisfacer, por sí o por otra persona, a consecuencia de un delito, de una culpa o de otra causa legal". La Real Academia Española también presenta como opción la "carga u obligación moral que resulta para alguien del posible yerro en caso o asunto determinado".

La responsabilidad, desde este ángulo, se presenta recurrentemente como la habilidad de responder, término que admite como significaciones las siguientes: "Contestar, satisfacer a lo que se pregunta o propone; Contestar a quien le llama; Satisfacer el argumento, duda, dificultad o demanda; Replicar a los requerimientos o afirmaciones de otra persona; Rendir o fructificar; Corresponder con una acción a lo realizado por otra; Estar obligada u obligarse a la pena y resarcimiento correspondientes al daño causado o a la culpa cometida". La cuestión de la responsabilidad funda, entonces, al menos una dimensión trascendente al individuo participando de su constitución como sujeto-en-relación. Si bien suponemos que incluye la necesidad de respuesta ante sí mismo, dicha capacidad de respuesta está originariamente enclavada en la relación sujeto-contexto con lo que supone la disociación entre quien o quienes deben responder, por un lado, y por el otro ante quien o quienes se espera que el sujeto responda. Advertimos así que la relación del sujeto con el contexto es, en cierta forma, la relación con algo o alguien que está al frente, en calidad de sujeto u objeto, pero separado. He ahí expresado, entonces, un rasgo típico del Proyecto de Modernidad que, con todos sus beneficios a defender y profundizar, se origina en y para la cultura europea.

Ahora bien, es evidente el esfuerzo ideológico dominante por resignificar este 
concepto a favor de cierta micro-responsabilización que debilita aquel enclave sujeto-contexto. Esto va en detrimento de todo posible avance hacia un mejor lugar conceptual al que comenzamos a pensar como sujeto-situación, donde la cuestión de la inscripción del joven en su entorno cobra un sentido clave. La propia noción de responsabilidad penal "juvenil" pone en evidencia el mencionado sesgo ya desde su formulación misma, centrada en el joven y sin mención de otros actores. Tiende, de manera harto excluyente, a ubicar la obligación de responder en el lugar del sujeto (joven, en este caso). Esta orientación general, no solo aplicable al orden penal, se advierte tanto en quienes parten de axiomas liberales fundamentales del tipo "la sociedad no existe, solo existen los individuos"; como también en quienes postulan ciertos conceptos religiosos de "persona" en medios de los cuales los condicionamientos y/o determinaciones relacionales son secundarias. Si bien no agotamos aquí la descripción de todas las posibilidades, se advierte que en ellas la posición de lo colectivo cede y crece la responsabilización individual o, a lo sumo, la responsabilización familiar. Por esta vía no es extraño concluir entonces en que los desocupados sean considerados culpables de no haberse convertido a las nuevas exigencias del mercado; los padres socialmente excluidos son culpables de no haber controlado a sus hijos antes de que terminaran en el delito; los viejos pobres son responsables de no haber aportado responsablemente para su jubilación. O a la inversa: los homosexuales no son responsables de una elección sino que son enfermos o desviados; las mujeres de los sectores populares son responsables de sus cuerpos siempre que los ajusten según mandatos de distintos organismos internacionales; los ciudadanos son responsablemente democráticos si reclaman a través de un abogado pero dejan de serlo si reclaman a través de un ilegal "piquete". ${ }^{4}$ Advertimos que tanto cuando se reconoce al sujeto como cuando se lo niega a través de la quita de protagonismo permanece esta idea de responsabilización individual.

Se trata, hasta aquí, de un simple ejercicio de análisis en situación con relación a ideas postuladas con ínfulas universales pero ¿cuán razonable es insistir en analizar estas ideas de responsabilidad universal para luego, en todo caso, aplicarlas a nuestra realidad? Como ya sabemos, este es un sendero plagado de sofismas entre los cuales traemos uno a título de ejemplo: "El problema es que no hay recursos", tras lo cual subyace la idea según la cual "cuando nos desarrollemos, esto será distinto y la 'responsabilización' podrá aplicarse”. No se advierte que la propia matriz de responsabilización individual es condición estructural necesaria para que en otros lugares (países centrales) existan recursos y que, entonces, no se trata de esperar a que la economía de mercado funcione para que el Estado pueda hacerse de los recursos e implementar los programas respectivos.

Es fundamental aceptar que situar la idea de responsabilización exige renunciar a "la ilusión de un espíritu sin máculas" (Casalla, 2004b: 2), totalmente liberado de las sombras que -en este campo- suelen aparecer toda vez que se postula dejar de lado los purismos unidisciplinares, jurídicos las más de las veces. En cierto sentido se trata de reemplazar este tipo de ficciones orientadoras que conllevan intrínsecamente la violencia de lo absoluto e impoluto y, en su lugar, colocar otras 
ficciones en las que se funde otro orden de lo real, y otras formas de entender la pureza del conocimiento. En esta concepción de lo puro reside ni más ni menos que su "posibilidad de ser" (Ídem: 3). Situar un problema conceptual no es tomarlo tal cual es en su formulación universal y adaptarlo a distintas realidades. Por el contrario, se trata de una formulación que tiene presente los componentes de carácter universal pero al servicio de la substancialidad local.

La situación no es, parafraseando a Casalla, un accidente sino sustancia de aquello que postulamos. Si nuestro objeto -la responsabilización penal juvenil- no es comprendido en el marco de una estructura historiográfica específica, difícilmente llegará a constituir lo que en apariencia postula: un avance en términos de vigencia de los Derechos Humanos. Si responsabilizar sigue formando parte del "magma" (Castoriadis, 1993) en el que se funden ejes conceptuales tales como la libertad equivaliendo a la propiedad privada para 'los más aptos', el borramiento de toda posible inter-culturalidad o la seguridad jurídica como condición de producciónconsumo antes que condición de ciudadanía solo avanzaremos hacia nuevas estaciones del camino que conduce al globaritarismo.

$\mathrm{Si}$ en cambio enriquecemos la mirada recorriendo el contexto latinoamericano, la idea de la responsabilización puede adquirir otros significados que incluyan la capacidad de respuesta del sujeto pero según las particularidades y capacidad de respuesta de la propia estructura en la que se encuentra inmerso. Si nos esforzamos por identificar rasgos de dicha situacionalidad encontramos por ejemplo que la díada conceptual Comunidad-Estado o Estado-Comunidad alberga un rico debate, con cierta tradición en Latinoamérica, que convendría retomar para esta cuestión. Como sabemos, tal discusión suele quedar dominada por la mirada occidental que en general es tomada por la Filosofía Política y gira, como punto de partida, en torno a las ideas de Thomas Hobbes, John Locke y Jacques Rousseau (entre otros, claro está). Tal versión prioriza al Estado como categoría conceptual, preferencia que se transforma en condición necesaria para el desarrollo de ideas propias del denominado liberalismo jurídico, terreno en el cual germina la universal idea de responsabilización penal juvenil. Constituye un avance, sin lugar a dudas, en términos de fortalecimiento de los Derechos Humanos pero en la propia naturaleza de dicho avance se inscribe el ariete que impide la materialización de tal progreso conceptual. De allí, en definitiva y como lo hemos dicho, la necesidad de situar el mencionado universal.

$\mathrm{Al}$ respecto dejamos apenas sugerida la línea de pensamiento que revaloriza el orden de lo comunitario, elaborada por distintos autores. Reformular el orden de los términos Comunidad y Estado se constituye en punto de urgencia. Armando Poratti ha escrito, en un trabajo compilado por Casalla y Hernando, que frente al declive de la idea de 'Sociedad' como reverso de la idea liberal de 'Estado'persiste la Comunidad. Tanto es así que "este reconocimiento de lo comunitario elevado al ámbito del planeta quizá sea una -o la última- posibilidad para este mundo planetario de superar el horizonte ontológico y fáctico de la nihilidad" (Poratti, 1996: 165). El pensamiento liberal, por estar construido a contramano de la realidad, no ha adver- 
tido el carácter mestizo de la Nación emplazada "en la América mestiza" (Kusch, 1998: 47); y sigue haciéndolo toda vez que cree ver herederos de la sangre europea donde aparecen aspectos físicos "blanqueados" (Argumedo, 2008).

Sin embargo, desde algunas de las fuentes de dicho carácter mestizo, distintas voces cobran fuerza y estimulan a pensar comportamientos individuales e institucionales. Estos últimos son construcciones que reflejan, ficcionalmente, aquella visión de un Estado que responde a modos occidentales de pensar y actuar. En ese contexto los dispositivos institucionales específicos (juzgados, tribunales u otros) intentan encajar en la realidad sus ideas "puras", pureza que -hemos dicho- corresponde poner en duda. Y precisemos: no nos referimos a tentativas del Estado sobre la realidad como totalidad sino de sus esfuerzos por ajustar las conductas de los sectores más mestizos entre los mestizos, utilizando para ello herramientas blancas.

Seguimos buscando rasgos de la referida situacionalidad y encontramos que en las historias vitales de los mestizos a los que está dirigida la noción de responsabilidad penal juvenil o, dicho del modo más corriente: "estos menores delincuentes", aparecen significativos puntos de contacto con pautas de convivencia comunitaria cuya legalidad no fue ni es fundamentalmente jurídica (en el sentido de norma jurídica). En el substrato cultural quizás radiquen mucha de las explicaciones a encontrar para aportar a la construcción de una genuina ficción orientadora que tome forma jurídica. Se sabe que la mayor parte de los delitos imputados a estos jóvenes están vinculados (¿casualmente?) a atentados contra la propiedad privada. ¿Qué es lo que se rompe cuando, desde trozos teóricos traídos del plano universal, se intenta dar cuenta de tal situación? Existen diversos estudios que dan cuenta de las dinámicas comunitarias y familiares. La lectura de ellos no puede conducirnos a otro lugar que a la base de nuestro pensamiento, es decir a aquellos axiomas que por ser tales no discutimos. Por ejemplo, las "vivencias comunitarias" (Barúa et al., 2008: 148) en las que se ensambla la cuestión de la femineidad pueden ser halladas en diversos grupos indígenas pero también, aunque con otras particularidades, en los barrios de los que proviene la población a la que -no nos engañemos- está dirigida la responsabilización penal juvenil. El lugar de la madre y su relación con el lugar del padre, la iniciación sexual precoz, los embarazos prematuros, etc., forman parte de una realidad a la que así se conceptualiza. Y así conceptualizada ella codifica los modos de respuesta oficial que develan, por un lado, hasta qué punto ese discurso no comprende la realidad y, por otro lado, hasta qué punto los sujetos de esa realidad no comprenden tal discurso, con lo que ello implica desde su posición de subordinación. Dado este quiebre comunicacional es difícil advertir cómo todo esto, mirado desde el modo occidental de pensar que impide advertir las interconexiones, deriva en un predominio de los atentados contra la propiedad privada. La discusión termina en una supuesta profundización de aspectos casi banales. Está, evidentemente, la cuestión de orden distributivo pero ¿se agota en ella o está enraizada en pautas que no coinciden con la ya mencionada noción liberal de propiedad privada?

Si pensamos en otros vínculos conceptuales nos podemos interrogar: ¿por qué 
estos jóvenes no respetan la autoridad? En definitiva saben que se levantan en armas contra varios poderes, algunos conscientes y otros inconscientes. De los primeros señalemos algunos: la policía, los guardias privados, los jueces, etc. ¿Por qué entonces? Y cuando esto ha sucedido y la sociedad le da otra oportunidad (razonamiento muy difundido): ¿Por qué en tantos casos "no la aprovechan”? ¿Qué dificulta tan gravemente esta intervención estatal? ¿Por qué no es eficaz? Rodolfo Kusch ha señalado que la potencialidad de penetrar el mundo para transformarlo no es oriunda de América sino de Europa, continente cuya racionalidad moderna ha construido un hombre confiado en sus propias fuerzas, en su inteligencia, es decir con pretensión de autonomía. Afirma el autor: "Logra así estructurar su acción sobre la base elemental de un impulso que apunta a un objetivo perfectamente delimitado dentro de un mundo sin secretos" (Kusch, 1998: 47). Esta relación entre impulso y objeto -diría el filósofo-no es la misma en el americano autóctono pues en él no ha operado la separación sujeto-objeto que sí ha sucedido en el racionalismo europeo. Dicho de otro modo, para el europeo la realidad se transforma en "un patio de objetos" (Tornay et al., 1986: 10), viendo al sujeto a través de la objetivación con lo que "cree distanciarse de su preocupación por el fundamento" (Ídem: 10). Como contrapartida y aunque con variaciones, la visión americana tiende a ser cósmica por lo que se trata de una cosmovisión que incluye fundamentalmente elementos tales como la madre tierra, en el caso de los pueblos originarios. El impulso en este caso, entonces, tiene otra orientación pues su construcción es otra.

Si trasladamos esto a las instancias judiciales podremos suponer que todo ciudadano occidentalizado tiene más posibilidades de afrontar adecuadamente un sistema de preguntas para las cuales podrá seleccionar respuestas relacionadas con hechos separados de la realidad, identificados, ubicados conceptualmente en un compartimiento estanco. Esto es así porque tanto las preguntas como las respuestas obedecen a una lógica jurídica acorde con la racionalidad específicamente moderna. Pero es sensato suponer que a mayor presencia de la cultura mestiza aquellas preguntas, hechas desde lugares de poder, obtendrán respuestas que fluyen entre contenidos inter-relacionados antes que seleccionar conceptos impulsados hacia objetos particulares. La opinión de Zaffaroni sigue esta línea pero es aún más radicalizada pues no lo piensa solo para la cultura mestiza sino para la cultura en general. Apoyándose en Foucault, entre otros, sostiene que la pregunta sirve a la construcción de una "interrogación selectiva" (Zaffaroni, 2007: 38) útil para dominar al objeto pero, a la vez, hace que el dominador caiga en una trampa. El dominado "no tiene la capacidad de responder selectivamente, responde con toda su entidad y también con toda su dignidad" (Ídem: 39). Y siendo que el dominador no está preparado para recibir dicha respuesta sufre "un ahogo por atragantamiento de respuestas" (Ídem: 40). La propia posición axiomática que ubica al preguntador en una posición de superioridad en relación con el preguntado, facultándolo para una interrogación señorial, conduce al equívoco que funciona como pedazo de ficción. Se potencia en nuestro caso, entonces, el conflicto en el encuentro de una concepción de poder con aspiraciones jerárquicas y la concepción "vegetal" (Kusch, 1998: 49) del mismo, propia de la América mestiza. Estamos así frente a 
otro rasgo constitutivo. Para el europeo, la concepción de autoridad es supuestamente prolija, vertical y descendente. Para el americano, en cambio, no existe un orden de referencia por lo que "hace nacer la autoridad de abajo hacia arriba" (Ídem: 49) con todas las implicancias que ello tiene en términos de prolijidad en su sentido occidental. Se advierte, sin demasiado esfuerzo, que esta concepción colisiona con el orden institucional existente, y se observa también con cierta facilidad cuánto de éste se expresa a diario ante cada caso de conflicto penal en el que aparece involucrado un joven. La facultad de preguntar sin ser preguntado, propia de los dispositivos institucionales, simboliza un campo de dificultades en términos de construcción de responsabilidad situada, en beneficio de la referida tendencia a la unilateralización de la responsabilización.

¿Cuál es el sentido, siendo esto así, de insistir con penar sus conductas? ¿Es posible obtener algún resultado? Podríamos avanzar profundizando estos tópicos e identificando otros pero bástenos, hasta aquí, con dejarlos señalados tentando preliminarmente la posibilidad de construcción de un objeto de estudio particularmente complejo. Esta complejidad habilita cuestiones a discutir teniendo presente la ya propuesta lectura culturalmente situada, tales como por ejemplo: aunque no se admite con facilidad es evidente que la pena, aún si la aceptáramos con su pretensión universalista, inclusive al ser aplicada sobre adultos, atraviesa una profunda crisis epistemológica y práctica pues sus resultados no son los anhelados por muchos ¿por qué, entonces, las derivaciones serían distintas si aplicáramos penas a los más jóvenes? Inclusive las disciplinas occidentales que se ocupan del desarrollo infanto-juvenil han descartado, mayoritariamente, la sanción como recurso central ¿por qué suponer que aquí los resultados serían otros?

Tenemos también que la pena unilateralmente aplicada no contribuye a construir responsabilidad y sí promueve temor reverencial en el mejor de los casos. ¿Por qué no explorar vías tales como la sanción restaurativa por reciprocidad, aspirando al protagonismo real del sujeto, más aún si la situamos en un contexto de re-valorización de la comunidad? Kazuko Kamii, investigadora de la Universidad de Alabama y discípula de Jean Piaget, expuso la conveniencia de evitar el castigo externo como recurso, detallando los efectos negativos. Como alternativa propuso la noción de "sanción por reciprocidad" (Kazuko Kamii, 1993), caracterizada por la construcción horizontal de compromisos ante los cuales el sujeto debe responder. Esto favorece el desarrollo de sujetos autónomos antes que heterónomos, lo que se potencia en nuestro caso si incorporamos la necesidad de lograr niveles satisfactorios de restauración de lo dañado, en el marco de los referidos compromisos horizontalmente construidos, y sin que esta restauración se confunda con la reposición en relación al perjuicio económico.

Las normas jurídicas por sí solas no garantizan mejoras en el orden real, y menos aún en nuestro contexto donde tienden -como escribe Casalla, según citamos antes- a transformarse en excesos ritualistas. Se requieren transformaciones en el orden de la institucionalidad pública que exceden lo normativo al punto de no admitir la idea de "cambiar al menos la ley" para mejorar "después" pues ese 
vago "después" ha fundado grandes relatos universales cuyas concretizaciones integrales vienen "demoradas" en demasía. Ejemplos: la CIDN a nivel internacional o la Ley de Protección Integral de los Derechos de la Niñez en Argentina fueron postulados como marcos para posteriores acciones que, no es difícil comprobarlo, avanzan muy lentamente; o bien esa lentitud es parte de la propia ficción. Pero entonces ¿por qué no habría de suceder lo mismo ante un sistema de responsabilidad penal juvenil no situado?

Lo problemático de esta cuestión surge en el entrecruzamiento de distintos planos, algunos referidos a lo jurídico, pero muchos otros vinculados a matrices culturales que generan formas de pensamiento, iatrogénicas prácticas policiales, penitenciarias, administrativas, etc. Sabemos que no es difícil encontrar derechos sociales vulnerados detrás de toda conducta juvenil delictiva ¿no corresponde admitir cierta co-responsabilidad y actuar en consecuencia?

Se advierte la complejidad del asunto pues, entre otras cosas, también se trata de valorar la existencia de componentes valiosos a nivel universal. De hecho, la propia Convención Internacional de los Derechos del Niño es un avance trascendental, aún incluyendo los debates mencionados anteriormente. Pero ¿cómo desarrollar formas de construcción de responsabilización juvenil situada incorporando aquellos avances? Posiblemente rompiendo con lógicas cuya transparencia epistemológica se construye sin el potencial que da la referencia empírica, y haciendo del accidente algo substancial, en los términos filosóficamente planteados por Casalla.

\section{5) Conclusiones}

Si renunciamos a la posición 'señorial'y admitimos tales necesidades podremos también admitir la siguiente cuestión: ¿cómo generar componentes científicos que, situacionalmente, fundamenten formas de intervenir de mayor calidad? Pensamos, claro está, en formas que respeten el piso internacional y nacionalmente establecido por el Pacto de San José de Costa Rica, con todas sus operativizaciones en términos de garantías procesales y substanciales. Pero ¿estamos en ese camino? Hemos sugerido que no, aún cuando importantes pasos se han dado. Los sistemas universalistas de responsabilidad penal juvenil son defendidos, fundamentalmente, a partir de que se constituyen en formas de respetar las garantías procesales y substanciales con relación a la niñez. Sin embargo le cabe la afirmación de Zaffaroni en cuanto que "las garantías en materia penal siempre avanzan respecto de algún vip ${ }^{5}$, pero no para los pobres tipos" (Zaffaroni, 2008).

¿Qué esperar de los centros de producción de ideas? Quizás, en primer lugar, que dejen de considerarse como tales pues, aunque lo son y deben seguir siéndolo, quizás esa propia definición implique cierto principio de adhesión al purismo teórico ya mencionado. También convendría recordar, nuevamente, a Rodolfo Kusch quien se pregunta “¿qué es la ciencia, sino una propuesta cultural más, proveniente de un Occidente que ordena la realidad según una determinada perspecti$v a$ ?" (Kusch, citado por Tornay, 1986: 14).

Se trata entonces de imaginar salidas que tengan presente el orden cultural en 
cuyo contexto producimos y en cuya trama se aplicaría lo producido. Es decir, generar formaciones conceptuales que aporten a la ficción orientadora que, en definitiva, se trata de construir en Argentina pero también en la América mestiza, y que no prosperará si no fija como condición necesaria el abandono de toda visión socialmente rupturista del tipo civilización o barbarie. Y cerremos, en relación con esto, parafraseando a Graciela Frigerio quien se preguntaba si, al recurrir a $l o$ penal, estamos ante el natural amor de los adultos por los niños o, en realidad, ante el odio de algunos adultos hacia algunos niños (Frigerio, 2008).

\section{Referencias}

1. Esta expresión admite una extensa discusión que aquí no se abordará pues disperíráa demasiado el objeto que se intenta delinear. Se la toma entonces en su sentido más corriente, comb́sinónimo de niños en situación de calle u otras expresiones similares.

2. Omitimos aquí la discusión referida a la conveniencia de utilizar la categoría conceptual 'pobre' u otras tales como 'excluídos' o 'desafiliados' pues nos alejaría de nuestro objeto.

3. El término, de uso en textos académicos, refiere a cierto impasse en la producción, sin importantes descensos u ascensos en términos de cantidad y/o calidad.

4. "Piquete": medida de fuerza básicamente consistente en obstaculizar total o parcialmente el tránsito sobre calles o rutas terrestres, incluyendo acciones tales como la quema de cubiertas de autos, pintadas en edificios de bancos, etc. Se trata de una medida particularmente confrontativa. En la República Argentina dicha medida generó la figura de los "Piqueteros", activistas usualmente pertenecientes a sectores altamente empobrecidos que -en el "Piquete"-actúan con pañuelos en sus cuellos y/o caras, portan palos que en ocasiones son utilizados en enfrentamientos con las fuerzas policiales, etc.

5. Expresión que designa la condición de ciudadano privilegiado por sus vínculos económicos, políticos, etc., y que le permite influir para obtener algún tipo de tratamiento diferenciado por parte de las distintas instituciones.

\section{Bibliografía}

A. ARGUMEDO (2008), Pensamiento Latinoamericano: los rasgos de un nuevo tiempo histórico, Curso Doctorado Ciencias Sociales, Paraná, UNER.

G. BARÚA et al. (2008), "El papel femenino en la convivencia wichí del Chaco Central”, en S. HIRSCH (comp.), Mujeres indigenas en la Argentina. Cuerpo, trabajo y poder, Buenos Aires, Biblos/ Culturalia.

M. CASALLA (2006), “Argentina: la trabajosa construcción de una nación”, Exposición en la XI Jornada de Pastoral Social de la Arquidiócesis de Buenos Aires, el 09/09/2006. Consultado el $12 / 12 / 08$, en:

www.aulas.ulpgc.es/index.php?pagina=aleman\&ver=documentos

M. CASALLA (2004a), "La construcción de un nuevo 'imaginario' latinoamericano en la era global", en Revista Peronistas. Consultado el 01/12/08, en: www.cepag.com.ar/pdf/peronistas 5

M. CASALLA (2004b), La filosofia latinoamericana como ejercicio de lo universal-situado. Consultado el 25/11/08, en:

www.aulas.ulpgc.es/index.php?pagina $=$ aleman\&ver=documentos

M. CASAlla (2003), América Latina en perspectiva. Dramas del pasado, huellas del presente, Buenos Aires, Osde-Altamira.

C. CASTORIADIS (1993), La institución imaginaria de la sociedad, Tomo II, Trad. Marco-Aurelio Galmarini, Barcelona, Tusquets.

COMITÉ ECONÓMICO-SOCIAL EUROPEO (2006), La prevención de la delincuencia juvenil, los modos de tratamiento y el papel de la Justicia del Menor en la Unión Europea, Bruselas.

E. GARCÍA MÉNDEZ (2006), Introducción a "Protección Integral de Derechos de Niñas, Niños y Adolescentes" (compilación), Buenos Aires, Editores del Puerto. 
R. CASTEL (2004), Las metamorfosis de la cuestión social: Una crónica del salariado, Trad. Jorge Piatigorsky, $1^{\mathrm{a}}$ edición, $1^{\mathrm{a}}$ reimpresión, Buenos Aires, Paidós.

L. FERRAJOLI (1995), Derecho y razón: Teoría del Garantismo Penal, Trad. Perfecto Andrés Ibáñez, Alfonso Ruiz Miguel, Juan Carlos Bayón Molina, Juan Terradillos Basaco y Rocío Cantarero Bandrés, Madrid, Trotta.

G. FRIGERIO (2008), “Complejidades de lo familiar", Conferencia en la Universidad Nacional del Litoral, Santa Fe, dictada el 10/11/08.

E. GOFFMAN (2004), Internados: ensayos sobre la situación social de los enfermos mentales, Trad. María Antonia Oyuela de Grant. $1^{\mathrm{a}}$ edición / $8^{\mathrm{a}}$ reimpresión, Buenos Aires, Amorrortu.

M. HELER (2005), Ciencia incierta. La producción social del conocimiento. $2^{\mathrm{a}}$ edición, Buenos Aires, Biblos.

C. KAZUKO KAMII (1993), El niño reinventa la aritmética: implicaciones de la teoría de Piaget, Trad. Genís Sánchez Barberán, $3^{\text {a }}$ edición, Madrid, Visor.

R. KUSCH (1998), La seducción de la barbarie, $2^{\mathrm{a}}$ edición, Buenos Aires, Fundación Ross.

G. LIPOVETSKY (1995), La era del vacio: Ensayos sobre el individualismo contemporáneo, $8^{\mathrm{a}}$ edición, Buenos Aires, Anagrama.

A. PORATTI (1996), "La eticidad de los pueblos", en M. CASALLA et al. (compiladores), La tecnología. Sus impactos en la educación y en la sociedad contemporánea, Buenos Aires, Sadop.

N. SHUMWAY (1993), La invención de la Argentina: Historia de una idea, Trad. César Aira, Buenos Aires, Emecé.

L. TORNAY et al. (1986), "Rodolfo Kusch: valoración de la diferencia", en L. JALFEN (director), Ensayos y debates, Buenos Aires, Escuela de Filosofía de Buenos Aires.

L. WACQUANT (2000), Las cárceles de la miseria, Trad. Horacio Pons, Buenos Aires, Manantial.

E. ZAFFARONI (2007), Apuntes sobre el pensamiento penal en el tiempo, Buenos Aires, Hammurabi.

(2008), No soy partidario de ninguna medida excepcional en estos juicios, Entrevista publicada por el diario "Página 12" de Argentina. Recuperada el 21/12/08 en: www.pagina12.com.ar/ diario/elpais/1-117123-2008-12-21-htr

Recibido: 03/09/2009. Aceptado: 07/09/2009 